7. Reprod. Fert. (1973) 33, 91-98

\title{
EFFECTS OF AVIAN AND MAMMALIAN PITUITARY PREPARATIONS ON INDUCTION OF OVULATION IN THE DOMESTIC FOWL, GALLUS DOMESTICUS
}

\author{
KIYOSHI IMAI \\ Faculty of Agriculture, Nagoya University, Chikusa-ku, Nagoya, Japan
}

(Received 6th March 1972)

\begin{abstract}
Summary. Fowl and mammalian pituitary preparations were injected intraperitoneally into hens ('ovulation-suppressed' following pretreatment with daily subcutaneous injections of PMSG) to determine their ovulation-inducing activities. Acetone-dried fowl (Gallus domesticus) and bovine anterior pituitaries (CAP and BAP), partially purified DEAEand CM-fractions prepared from CAP and CAP homogenate, and ovine NIH-FSH and -LH were used as the test preparations.

Acetone-dried CAP induced multiple ovulations from three to five follicles in the ovulation-suppressed hens pretreated with PMSG, whereas no ovulation occurred after the injection of BAP. The DEAEfraction exhibited about the same activity as the CAP homogenate in the induction of multiple ovulations from three to six follicles, but the activity of the CM-fraction was considerably lower than that of the CAP homogenate and DEAE-fraction. Ovine FSH did not induce ovulation, whilst a single injection of ovine $\mathrm{LH}$ resulted in ovulations from one to three follicles. The number of ovulating follicles induced by the preparations originating from CAP was significantly more than that induced by ovine LH.
\end{abstract}

\section{INTRODUCTION}

It is well known that mammalian pituitary gonadotrophins can cause ovulation in the hen. Fraps, Olsen \& Neher (1942) and Fraps, Riley \& Olsen (1942) reported that premature ovulation occurred in normal laying hens after the intravenous injection of equine $\mathrm{LH}$ or a commercial preparation of mammalian gonadotrophins. A forced ovulation was also induced by the administration of ovine LH in hypophysectomized hens (Opel \& Nalbandov, 1961b), in fasting hens (Hosoda, Kaneko, Mogi \& Abe, 1956) and in hens with ovulation-block pretreated with an anaesthetic drug, phenobarbital sodium (Tanaka, Kamiyoshi \& Wolford, 1970). Ferrando \& Nalbandov (1969) found that local injection of a mixture of FSH and LH into the follicle wall effected ovulation in hens pretreated systemically with an adrenergic blocking drug, dibenzyline.

It has been reported that fowl (Gallus domesticus) pituitary preparations were more effective than mammalian preparations in causing a substantial follicular growth in immature pullets (Das \& Nalbandov, 1955; Taber, Claytor, Knight, 
Gambrell, Flowers \& Ayers, 1958), in pullets with quiescent ovaries produced by treatment with Methallibure (Imai, 1972) or in hypophysectomized hens (Opel \& Nalbandov, 1961a). Imai (1972), investigating the effects on follicular growth of partially purified fowl and ovine gonadotrophins and of crude fowl and bovine pituitaries, suggested that the superiority of the fowl preparations in stimulating ovarian activity in the hen was due to the difference between avian and mammalian gonadotrophins.

Fraps \& Riley (1942) reported an experimental method of inducing multiple ovulations in the hen and thereafter, this technique was utilized for studies on induced ovulation in this bird (Fraps, Riley \& Olsen, 1942) and in the quail (Opel, 1966). Fraps \& Riley (1942) found that treatment with PMSG greatly stimulated follicular growth and suppressed ovulation in laying birds, and they further demonstrated that, if an appropriate substance for induction of ovulation was given to these hens, ovulation occurred in many follicles. The present work was carried out to demonstrate the effects of crude or partially purified fowl and mammalian gonadotrophin preparations on ovulation in hens pretreated with PMSG. The ovulation-inducing effect was estimated by two criteria, the occurrence of ovulation and the number of follicles in which ovulation occurred.

\section{MATERIALS AND METHODS}

Single-comb White Leghorn laying pullets, aged 9 to 11 months, were kept in individual cages exposed to $14 \mathrm{hr}$ light and $10 \mathrm{hr}$ dark/day. Food and water were freely available. Hens to be used for the pretreatment with PMSG were selected on the basis of having regular laying patterns for 3 to 4 weeks before the experiment and egg sequences ranging from four to seven eggs.

In preliminary experiments, laying hens were treated with consecutive daily subcutaneous injections of PMSG (Peamex, Tomoda Pharmac. Co., Tokyo) at daily doses of 25 to 300 i.u. to maintain follicular growth whilst suppressing normal ovulation. The interruption of ovulation did not occur with daily injections of 25 or 50 i.u. PMSG. When 75 i.u. or more was administered daily, the egg laying ceased in almost all the hens within 4 to 8 days after the start of the injections. It was also found by examination post mortem 3 days after the cessation of egg laying that four to seven large yellow follicles ( $>3 \mathrm{~cm}$ diameter) and no atretic follicles were present in the ovaries of hens that had been receiving 75 i.u. PMSG daily; several large atretic follicles were observed in the ovaries if autopsy was carried out between the 5th and 10th days after the end of laying On the basis of these preliminary results, the laying pullets were pretreated with a daily subcutaneous injection of 75 i.u. PMSG until the 2nd day after the cessation of egg laying. A period of pretreatment with PMSG ranged from 4 to 13 days for a total of 173 hens, depending on their egg-laying conditions.

Fowl or mammalian pituitary preparations were given intraperitoneally to the PMSG-pretreated hens in the afternoon (14.00 to 16.00 hours) of the 3rd day after the cessation of egg laying (24 hr after the final injection of PMSG), in order to determine the ovulation-inducing effect of the preparations. Immediately before the injection, no egg in the oviduct was detected by palpation in 
any of the hens that were treated. The hens were killed 18 to $20 \mathrm{hr}$ after the injection and the ovaries, oviducts and yolks which had ovulated were carefully removed and collected. The ovaries were weighed and ruptured follicles, normal yellow follicles $(>3 \mathrm{~cm}$ diameter) and acutely formed atretic follicles were counted. Yolks which existed in the oviduct and in the abdominal cavity were also counted and weighed.

\section{Pituitary preparations}

Fowl anterior pituitary (CAP) collected from broilers of both sexes was stored for 2 weeks in cold acetone (replaced by fresh acetone every 3 days) and then dried and stored in a desiccator. Immediately before use in the test, the acetone-dried CAP was homogenized in cold physiological saline in an ice-box and centrifuged at $4^{\circ} \mathrm{C}$; the supernatant was used as the injection material. Most of the CAP collected was quick-frozen and stored at $-20^{\circ} \mathrm{C}$. The frozen CAP was used as a source for obtaining partially purified preparations of fowl gonadotrophins.

Partially purified fowl gonadotrophin fractions were obtained by the use of carboxymethyl (CM)- or diethylaminoethyl (DEAE)-cellulose according to the procedure described previously (Imai, 1972). Batches, consisting of $2 \mathrm{~g}$ frozen CAP, were extracted with $6 \%$ ammonium acetate in $40 \%$ ethanol, $\mathrm{pH} 5 \cdot 1$, and a glycoprotein extract was obtained by the addition of 5 vol. cold absolute ethanol. The glycoprotein extract was purified further by batchwise adsorption onto CM-cellulose in $4 \mathrm{~mm}$-ammonium acetate, $\mathrm{pH} 5 \cdot 5$, the final product being named the CM-fraction. A DEAE-fraction was also prepared from the glycoprotein extract by the use of DEAE-cellulose in 0.05 M-disodium hydrogen phosphate, $\mathrm{pH} 7 \cdot 5$. A desired amount of CM- or DEAE-fraction was dissolved in $1 \mathrm{ml}$ physiological saline immediately before the injection.

Bovine anterior pituitary (BAP) was placed in acetone for several weeks, then dried, crushed and stored in a desiccator. The pool of dried pieces of BAP was homogenized in cold saline and centrifuged, the supernatant being injected into hens pretreated with PMSG. Ovine FSH (NIH-FSH-S7) and LH (NIH-LHS15) were also used for injection, alone or in combination. An injected amount of these hormones was prepared in $1 \mathrm{ml}$ saline.

\section{RESULTS}

The effects of acetone-dried CAP and BAP on the induction of ovulation in hens pretreated with PMSG are shown in Table 1 . Neither ovulation nor atresia occurred in the ovaries of five control hens which received $1 \mathrm{ml}$ saline intraperitoneally under the same conditions as the experimental hens. Ovulation was induced in all the hens that received acetone-dried CAP in a dose of more than $2.5 \mathrm{mg}$ on a dry-weight basis. Moreover, it was obvious that the increase in the number of ovulating follicles was related to the dose used, within the range from 1.25 to $10 \mathrm{mg}$ CAP. By counting the ruptured follicles in the ovaries, five ovulations were observed in two hens, one being in the group injected with $10 \mathrm{mg}$ CAP and the other in the group injected with $20 \mathrm{mg}$ CAP. In the ovaries of the remaining four hens receiving 10 or $20 \mathrm{mg}$ acetone-dried CAP, 
Table 1. Effects of acetone-dried GAP and BAP on induction of ovulation in hens pretreated with PMSG

\begin{tabular}{|c|c|c|c|c|c|}
\hline \multirow[b]{2}{*}{$\begin{array}{c}\text { Dose and preparation } \\
\text { injected }\end{array}$} & \multirow[b]{2}{*}{$\begin{array}{l}\text { No. of } \\
\text { hens }\end{array}$} & \multicolumn{2}{|r|}{ Ovulation } & \multicolumn{2}{|c|}{ No. of follicles appearing } \\
\hline & & $\begin{array}{l}\text { No. of } \\
\text { hens }\end{array}$ & $\begin{array}{c}\text { No. of ovulating } \\
\text { follicles/hen } \\
\text { Mean } \pm \text { S.E. }\end{array}$ & $\begin{array}{l}\text { Normal* } \\
\text { Mean } \pm \text { S.E. }\end{array}$ & $\begin{array}{c}\text { Atretic } \dagger \\
\text { Mean } \pm \text { S.E. }\end{array}$ \\
\hline $\begin{array}{rl}1.25 & \mathrm{mg} \text { CAP } \\
2.5 & \mathrm{mg} \text { CAP } \\
5.0 & \mathrm{mg} \text { CAP } \\
10.0 & \mathrm{mg} \text { CAP } \\
20.0 & \mathrm{mg} \mathrm{CAP}\end{array}$ & $\begin{array}{l}4 \\
3 \\
3 \\
3 \\
3\end{array}$ & $\begin{array}{l}3 \\
3 \\
3 \\
3 \\
3\end{array}$ & $\begin{array}{l}1 \cdot 7 \pm 0 \cdot 3 \\
2 \cdot 3 \pm 0.3 \\
2 \cdot 7 \pm 0 \cdot 3 \\
3 \cdot 7 \pm 0.9 \\
3 \cdot 7 \pm 0.7\end{array}$ & $\begin{array}{l}\text { (4) } 2 \cdot 5 \pm 0 \cdot 6 \\
\text { (3) } 2 \cdot 7 \pm 0.3 \\
\text { (3) } 2 \cdot 3 \pm 0.7 \\
\text { (3) } 2 \cdot 0 \pm 0.6 \\
\text { (3) } 1 \cdot 3 \pm 0.3\end{array}$ & $\begin{array}{l}\text { (2) } 2 \cdot 0 \\
\text { (0) } 0.0 \\
\text { (2) } 2 \cdot 0 \\
\text { (1) } 1.0 \\
\text { (2) } 2 \cdot 0\end{array}$ \\
\hline $\begin{array}{rc}20.0 & \mathrm{mg} \text { BAP } \\
40.0 & \mathrm{mg} \text { BAP } \\
80.0 & \mathrm{mg} \text { BAP } \\
160.0 & \mathrm{mg} \mathrm{BAP}\end{array}$ & $\begin{array}{l}3 \\
3 \\
3 \\
3\end{array}$ & $\begin{array}{l}0 \\
0 \\
0 \\
0\end{array}$ & $\begin{array}{l}0.0 \\
0.0 \\
0.0 \\
0.0\end{array}$ & $\begin{array}{l}\text { (3) } 5.3 \pm 0.9 \\
\text { (3) } 5.3 \pm 0.3 \\
\text { (3) } 4 \cdot 7 \pm 0.3 \\
\text { (3) } 4.3 \pm 1.3\end{array}$ & $\begin{array}{l}\text { (0) } 0.0 \\
\text { (1) } 2 \cdot 0 \\
\text { (3) } 2 \cdot 0 \pm 0.6 \\
\text { (3) } 2 \cdot 3 \pm 0.3\end{array}$ \\
\hline Saline & 5 & 0 & 0.0 & (5) $4.8 \pm 0.5$ & (0) 0.0 \\
\hline
\end{tabular}

For abbreviations, see text. Figures in parentheses are numbers of hens with normal or atretic follicle(s).

* Normal yellow follicles of more than $3 \mathrm{~cm}$ diameter.

$\uparrow$ Acutely formed yellowish atretic follicles.

three ruptured follicles were counted. By contrast, no ovulation occurred in the hens treated with acetone-dried BAP at four dose levels between 20 and 160 $\mathrm{mg}$. In all the ovaries of hens injected with the higher doses of 80 and $160 \mathrm{mg}$ $\mathrm{BAP}$, one to three atretic follicles, regarded as having been produced within the post-injection period, were observed.

Table 2 shows the ovulation-inducing effects of CM- and DEAE-fractions and

Table 2. Effects of CM- and DEAE-fractions and CAP homogenate on induction of ovulation in hens pretreated with PMSG

\begin{tabular}{|c|c|c|c|c|c|}
\hline \multirow[b]{2}{*}{$\begin{array}{l}\text { Dose and preparation } \\
\text { injected }\end{array}$} & \multirow[b]{2}{*}{$\begin{array}{c}\text { No. of } \\
\text { hens }\end{array}$} & \multicolumn{2}{|r|}{ Ovulation } & \multicolumn{2}{|c|}{ No. of follicles appearing } \\
\hline & & $\begin{array}{c}\text { No. of } \\
\text { hens }\end{array}$ & $\begin{array}{l}\text { No. of ovulating } \\
\text { follicles/hen } \\
\text { Mean } \pm \text { S.E. }\end{array}$ & $\begin{array}{c}\text { Normal }^{*} \\
\text { Mean } \pm \text { S.E. }\end{array}$ & $\begin{array}{c}\text { Atretic* } \\
\text { Mean }\end{array}$ \\
\hline $\begin{array}{l}10 \mathrm{mg} \text {. CAP homogenate } \\
25 \mathrm{mg} \text {, CAP homogenate } \\
50 \mathrm{mg} \text {, CAP homogenate } \\
100 \mathrm{mg} \text {, CAP homogenate } \\
200 \mathrm{mg} \text {, CAP homogenate } \\
400 \mathrm{mg} \text {, CAP homogenate }\end{array}$ & $\begin{array}{l}4 \\
4 \\
5 \\
5 \\
5 \\
4\end{array}$ & $\begin{array}{l}3 \\
4 \\
5 \\
5 \\
5 \\
4\end{array}$ & $\begin{array}{l}1 \cdot 3 \pm 0.3 \\
2 \cdot 0 \pm 0.4 \\
2 \cdot 8 \pm 0.4 \\
3 \cdot 8 \pm 0.4 \\
4 \cdot 0 \pm 0.5 \\
3 \cdot 8 \pm 0.5\end{array}$ & $\begin{array}{l}\text { (4) } 2 \cdot 8 \pm 0.5 \\
\text { (3) } 2 \cdot 7 \pm 1 \cdot 6 \\
\text { (5) } 2 \cdot 6 \pm 0 \cdot 4 \\
\text { (1) } 3 \cdot 0 \\
\text { (4) } 2 \cdot 3 \pm 0.9 \\
\text { (3) } 2 \cdot 7 \pm 0.9\end{array}$ & $\begin{array}{l}\text { (2) } 1.0 \\
\text { (1) } 1.0 \\
\text { (0) } 0.0 \\
\text { (2) } 1.0 \\
\text { (0) } 0.0 \\
\text { (0) } 0.0\end{array}$ \\
\hline $\begin{array}{l}100 \mathrm{mg} \text { CAPcq., CM-fraction } \\
200 \mathrm{mg} \text { CAPeq. CM-fraction } \\
400 \mathrm{mg} \text { CAPeq., CiM-fraction } \\
800 \mathrm{mg} \text { CAPeq., CM-fraction }\end{array}$ & $\begin{array}{l}3 \\
4 \\
4 \\
3\end{array}$ & $\begin{array}{l}0 \\
2 \\
3 \\
3\end{array}$ & $\begin{array}{l}0 \cdot 0 \\
2 \cdot 0 \\
2 \cdot 0 \pm 0 \cdot 6 \\
3 \cdot 0 \pm 0 \cdot 0\end{array}$ & $\begin{array}{l}\text { (3) } 4 \cdot 7 \pm 0 \cdot 9 \\
\text { (4) } 4 \cdot 3 \pm 1 \cdot 0 \\
3 \cdot 3 \pm 1 \cdot 3 \\
\text { (3) } 2 \cdot 7 \pm 0 \cdot 3\end{array}$ & $\begin{array}{l}\text { (1) } 1.0 \\
\text { (2) } 1.0 \\
\text { (1) } 1.0 \\
\text { (2) } 1.0\end{array}$ \\
\hline 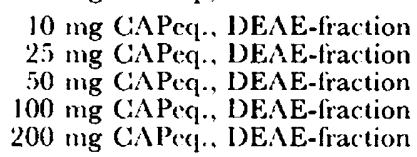 & $\begin{array}{l}3 \\
3 \\
3 \\
3 \\
3\end{array}$ & $\begin{array}{l}3 \\
3 \\
3 \\
3 \\
3\end{array}$ & $\begin{array}{l}2 \cdot 0 \pm 0 \cdot 0 \\
2 \cdot 3 \pm 0 \cdot 3 \\
3 \cdot 3 \pm 0 \cdot 7 \\
4 \cdot 0 \pm 0 \cdot 6 \\
4 \cdot 0 \pm 1 \cdot 0\end{array}$ & $\begin{array}{l}\text { (3) } 3 \cdot 3 \pm 0 \cdot 3 \\
\text { (2) } 2 \cdot 5 \\
\text { (2) } 2 \cdot 5 \\
\text { (1) } 2 \cdot 0 \\
\text { (2) } 1 \cdot 5\end{array}$ & $\begin{array}{l}\text { (1) } 2 \cdot 0 \\
\text { (2) } 1.5 \\
\text { (2) } 1.0 \\
\text { (1) } 1 \cdot 0 \\
\text { (1) } 1.0\end{array}$ \\
\hline Saline & 5 & 0 & 0.0 & (5) $4 \cdot 6 \pm 0 \cdot 4$ & (1) 1.0 \\
\hline
\end{tabular}

For abbreviations, sec text. Figures in parentheses are numbers of hens with normal or atretic follicle(s).

* See the footnotes to Table 1. 
of CAP homogenate, which was used as the starting material for obtaining these two fractions. The CAP homogenate and DEAE-fraction were almost equally active in the induction of ovulation in hens pretreated with PMSG, as judged either by the ovulation rate or by the numbers of follicles in which ovulation had occurred, the same doses of the two preparations producing about the same results. A dose of the CM-fraction corresponding to the product from $800 \mathrm{mg}$ CAP as starting material was required to cause a level of ovulation comparable to that obtained with $50 \mathrm{mg}$ CAP homogenate or $50 \mathrm{mg}$ CAP equivalent of DEAE-fraction. In the groups receiving CAP and DEAE-fraction, the number of ovulating follicles increased gradually as the doses increased, reaching a maximum in the groups receiving $100 \mathrm{mg}$ CAP homogenate or $100 \mathrm{mg}$ CAP equivalent of DEAE-fraction. A similar tendency was found in the groups

Table 3. Effects of ovine LH (NIH-LH-S15) and FSH (NIH-FSH-S7) on induction of ovulation in hens pretreated with PMSG

\begin{tabular}{|c|c|c|c|c|c|}
\hline \multirow[b]{2}{*}{$\begin{array}{c}\text { Dose and preparation } \\
\text { injected }\end{array}$} & \multirow[b]{2}{*}{$\begin{array}{l}\text { No. } \\
\text { of } \\
\text { hens }\end{array}$} & \multicolumn{2}{|c|}{ Ovulation } & \multicolumn{2}{|c|}{ No. of follicles appearing } \\
\hline & & $\begin{array}{l}\text { No. } \\
\text { of } \\
\text { hens }\end{array}$ & $\begin{array}{c}\text { No. of ovulating } \\
\text { follicles/hen } \\
\text { Mean } \pm \text { S.E. }\end{array}$ & $\begin{array}{c}\text { Normal* } \\
\text { Mean } \pm \text { S.E. }\end{array}$ & $\begin{array}{c}\text { Atretic* } \\
\text { Mean } \pm S . E .\end{array}$ \\
\hline $\begin{array}{l}25 \mu \mathrm{g} \mathrm{LH} \\
50 \mu \mathrm{g} \mathrm{LH} \\
100 \mu \mathrm{g} \mathrm{LH} \\
200 \mu \mathrm{g} \mathrm{LH} \\
400 \mu \mathrm{g} \mathrm{LH} \\
800 \mu \mathrm{g} \mathrm{LH}\end{array}$ & $\begin{array}{l}3 \\
6 \\
6 \\
5 \\
4 \\
3\end{array}$ & $\begin{array}{l}0 \\
5 \\
6 \\
5 \\
4 \\
3\end{array}$ & $\begin{array}{l}0.0 \\
1 \cdot 0 \pm 0.0 \\
1 \cdot 2 \pm 0.2 \\
2 \cdot 0 \pm 0.3 \\
2 \cdot 0 \pm 0.4 \\
2 \cdot 3 \pm 0.7\end{array}$ & $\begin{array}{l}\text { (3) } 5.0 \pm 1.2 \\
\text { (6) } 2.0 \pm 0.4 \\
\text { (5) } 2.6 \pm 1.0 \\
\text { (5) } 2.0 \pm 0.5 \\
\text { (4) } 2.5 \pm 0.6 \\
\text { (3) } 1.7 \pm 0.3\end{array}$ & $\begin{array}{l}\text { (0) } 0.0 \\
\text { (6) } 2 \cdot 3 \pm 0.5 \\
\text { (4) } 3 \cdot 0 \pm 0 \cdot 7 \\
\text { (5) } 1 \cdot 6 \pm 0 \cdot 6 \\
\text { (4) } 1.5 \pm 0.5 \\
\text { (2) } 2 \cdot 0\end{array}$ \\
\hline $\begin{array}{l}50 \mu \mathrm{g} \text { FSH } \\
100 \mu \mathrm{g} \text { FSH } \\
200 \mu \mathrm{g} \text { FSH } \\
400 \mu \mathrm{g} \text { FSH }\end{array}$ & $\begin{array}{l}3 \\
3 \\
3 \\
3\end{array}$ & $\begin{array}{l}0 \\
0 \\
0 \\
0\end{array}$ & $\begin{array}{l}0 \cdot 0 \\
0 \cdot 0 \\
0 \cdot 0 \\
0 \cdot 0\end{array}$ & $\begin{array}{l}\text { (3) } 5 \cdot 7 \pm 0.3 \\
\text { (3) } 5 \cdot 3 \pm 0.3 \\
\text { (3) } 4 \cdot 7 \pm 0.3 \\
\text { (3) } 3 \cdot 3 \pm 0.3\end{array}$ & $\begin{array}{l}\text { (0) } 0 \cdot 0 \\
\text { (1) } 1 \cdot 0 \\
\text { (3) } 1 \cdot 3 \pm 0 \cdot 3 \\
\text { (3) } 2 \cdot 7 \pm 0 \cdot 3\end{array}$ \\
\hline $\begin{array}{l}200 \mu \mathrm{g} \mathrm{LH}+100 \mu \mathrm{g} \text { FSH } \\
200 \mu \mathrm{g} \mathrm{LH}+200 \mu \mathrm{g} \text { FSH } \\
200 \mu \mathrm{g} \mathrm{LH}+400 \mu \mathrm{g} \mathrm{FSH}\end{array}$ & $\begin{array}{l}4 \\
3 \\
3\end{array}$ & $\begin{array}{l}4 \\
3 \\
3\end{array}$ & $\begin{array}{l}2 \cdot 5 \pm 0.3 \\
2 \cdot 0 \pm 0.6 \\
2 \cdot 0 \pm 0.6\end{array}$ & $\begin{array}{l}\text { (4) } 2 \cdot 0 \pm 0.4 \\
\text { (3) } 1 \cdot 3 \pm 0 \cdot 3 \\
\text { (2) } 1 \cdot 5\end{array}$ & $\begin{array}{l}\text { (4) } 2 \cdot 5 \pm 0 \cdot 6 \\
\text { (3) } 2 \cdot 7 \pm 0 \cdot 3 \\
\text { (3) } 3 \cdot 0 \pm 0 \cdot 6\end{array}$ \\
\hline Saline & 5 & 0 & 0.0 & (5) $4 \cdot 4 \pm 0 \cdot 2$ & (0) 0.0 \\
\hline
\end{tabular}

Figures in parentheses are numbers of hens with normal or atretic follicle(s).

* See the footnotes to Table 1.

receiving CM-fraction within the dose range of 200 to $800 \mathrm{mg}$ CAP equivalent. Three to six multiple ovulations occurred in all the twenty hens in five groups injected with 100,200 and $400 \mathrm{mg}$ CAP homogenate, and 100 and $200 \mathrm{mg}$ CAP equivalent of DEAE-fraction. On the other hand, formation of atretic follicles was found in few ovaries of hens which received the preparation originating from CAP.

The ovulation-inducing effects of ovine FSH and/or LH are shown in Table 3. Ovine FSH in the four dose levels used did not cause ovulation in any hens pretreated with PMSG. No sign of ovarian stimulation (induction of ovulation or formation of atretic follicles) was seen in the group injected with the lowest dose of FSH, whilst several large atretic follicles were acutely formed in all the hens treated with the higher doses (200 and $400 \mu \mathrm{g} \mathrm{FSH}$ ). A single administration of ovine $\mathrm{LH}$, with the dose levels of more than $50 \mu \mathrm{g}$, was effective in 
inducing ovulation in the PMSG-pretreated hens. It was also noted that in the groups injected with $\mathrm{LH}$, the number of ovulating follicles increased gradually in proportion to the doses within the range from 50 to $200 \mu \mathrm{g}$. Injection with $\mathrm{LH}$ at doses over $200 \mu \mathrm{g}$, however, produced no further increase in the number of ovulating follicles. By counting the ovulating follicles in twelve hens receiving 200, 400 and $800 \mu \mathrm{g} \mathrm{LH}$, three multiple ovulations were found in each of four hens, two ovulations in each of five hens, and one in each of three hens. When the number of ovulating follicles $(2 \cdot 1 \pm 0 \cdot 23)$ in these twelve hens, which received $\mathrm{LH}$ in a sufficient dose for induction of multiple ovulations, was compared with that in twenty-six hens $(3 \cdot 8 \pm 0 \cdot 21)$ receiving fowl pituitary preparations in the doses which produced maximum ovulations (including seven groups injected with 10 and $20 \mathrm{mg}$ acetone-dried CAP, 100, 200 and 400 mg CAP homogenate, and 100 and $200 \mathrm{mg} \mathrm{CAP}$ equivalent of DEAE-fraction), a highly significant difference was found between the two groups $(P<0.001)$. Moreover, even if FSH in the doses shown in Table 3 was administered together with a sufficient dose of $\mathrm{LH}$ to cause multiple ovulations, the number of ovulating follicles in these hens did not increase as much as in hens which received fowl pituitary preparations.

In a total of seventy-nine hens in which multiple ovulations occurred in the ovaries after the injection of fowl and mammalian pituitary preparations, only one egg was found in the oviduct and a single yolk existed in all the eggs, except for one which contained two yolks. The remaining yolks were recovered from the body cavity. The average weight of the yolks recovered from the oviduct of hens in which multiple ovulations occurred was $18.2 \pm 0.4 \mathrm{~g}$, ranging from 13.1 to $24.1 \mathrm{~g}$. On the other hand, the average yolk weight in hens in which ovulation occurred in only one follicle was $21 \cdot 3 \pm 0 \cdot 4 \mathrm{~g}$, ranging from $16 \cdot 3$ to $24 \cdot 2 \mathrm{~g}$. The difference in yolk weight between these two groups was significant statistically $(P<0.001)$.

\section{DISCUSSION}

In the present work, the ovulation-inducing activity of the CM-fraction was markedly low compared with that of the CAP homogenate and of the DEAEfraction. The CAP homogenate and the DEAE-fraction had almost equal activities for the induction of ovulation. Recently, it was demonstrated that CM- and DEAE-fractions exhibited about equal activity in causing follicular growth in the regressed ovary of hens treated with Methallibure (Imai, 1972). These findings indicate that the extent of the follicular growth-inducing and ovulation-inducing activities in the two fractions originating from fowl pituitary are considerably different from each other, and suggest that the CM-fraction contains predominantly the follicular growth-inducing activity whilst the ovulation-inducing activity in fowl pituitary is concentrated mainly in the DEAE-fraction.

It was apparent that ovine LH was as effective as the fowl pituitary preparations in inducing ovulation since ruptured follicles were found in all the hens receiving $\mathrm{LH}$ in doses of more than $100 \mu \mathrm{g}$. On the other hand, ovine FSH, at the dose levels used, did not have any effect in causing ovulation in the 
PMSG-pretreated hens, whereas several large atretic follicles, regarded as being acutely formed by the injection, were noted in all the hens which received the higher doses of FSH.

By using the ovulation-suppressed hens produced by pretreatment with PMSG, the ovulation-inducing effect of test preparations could be estimated by observing the number of multiple ovulations as well as the rate of occurrence of ovulation in the different groups. As many as six multiple ovulations occurred in hens which received fowl pituitary preparations, whilst the rupture of only three follicles was the maximum number in hens receiving ovine LH. A significant difference in the number of ovulating follicles existed between the two groups treated with fowl gonadotrophins and ovine $\mathrm{LH}$ in sufficient doses to cause multiple ovulations. Moreover, when various doses of FSH were added to a dose of LH sufficient to induce multiple ovulation, the numbers of ovulating follicles did not increase as they did in hens receiving the preparations originating from CAP. The results of the present study show that fowl pituitary gonadotrophin(s) were more efficient in causing ovulation in hens pretreated with PMSG than mammalian gonadotrophins given singly or in combination.

Only one egg was ever found in the oviduct in all the hens in which multiple ovulations occurred and a single yolk was present in every egg except one. These findings agree very well with the observations of Fraps \& Riley (1942), and indicate that, in the circumstances of the present study, the hen's oviduct generally fails to accept two or more yolks simultaneously. On the other hand, the yolks of the oviducal eggs of hens with multiple ovulations were significantly lighter and more variable in weight than those of eggs resulting from single ovulations. Since, in the event of a single ovulation, the largest follicle in the ovary is thought to ovulate, the above results would suggest that the oviduct (infundibulum) does not always catch the largest yolk when multiple ovulation occurs.

\section{AGKNOWLEDGMENTS}

The author wishes to thank the National Institute of Health, U.S.A., for supplying NIH-FSH-S7 and NIH-LH-S15. I am grateful to Dr S. Nakajo for helpful discussions and to Mr M. Wakamatsu and Mrs F. A. Nosseir for technical assistance in the present experiments. Thanks are due to $\mathrm{Mr} \mathrm{T}$. Niwa, $\mathrm{Mr} \mathrm{K}$. Kawakura, Mr J. Ando and Mr R. Ogawa for collecting fowl anterior pituitaries. This work was supported partly by a Grant in Aid of Scientific Research from the Ministry of Education of Japan.

\section{REFERENGES}

Das, B. C. \& Nalbandov, A. V. (1955) Responses of ovaries of immature chickens to avian and mammalian gonadotrophins. Endocrinology, 57, 705.

Ferrando, G. \& Nalbandov, A. V. (1969) Direct effect on the ovary of the adrenergic blocking drug dibenzyline. Endocrinology, 85, 38.

Fraps, R. M., Olsen, M. W. \& Neher, B. H. (1942) Forced ovulation of normal ovarian follicles in the domestic fowl. Proc. Soc. exp. Biol. Med. 50, 308.

Fraps, R. M. \& Riley, G. M. (1942) Hormone-induced ovulation in domestic fowl. Proc. Soc. exp. Biol. Med. 49, 253.

Fraps, R. M., Riley, G. M. \& Olsen, M. W. (1942) Time required for induction of ovulation following intravenous injection of hormone preparations in fowl. Proc. Soc. exp. Biol. Med. 50, 313. 
Hosoda, T., Kaneko, T., Mogi, K. \& ABE, T. (1956) Forced ovulation in gonadotrophin-treated fasting hens. Proc. Soc. exp. Biol. Med. 92, 360.

IMAI, K. (1972) Effects of avian and mammalian pituitary preparations on follicular growth in hens treated with Methallibure or fasting. F. Reprod. Fert. 31, 387.

Opel, H. (1966) The timing of oviposition and ovulation in the quail (Coturnix coturnix japonica). Br. Poult. Sci. 7, 29.

Opel, H. \& Nalbandov, A. V. (1961a) Follicular growth and ovulation in hypophysectomized hens. Endocrinology, 69, 1016.

Opel, H. \& Nalbandov, A. V. (1961b) Ovulability of ovarian follicles in the hypophysectomized hen. Endocrinology, 69, 1029.

Taber, E., Claytor, M., Knight, J., Gambrell, D., Flowers, J. \& Ayers, G. (1958) Ovarian stimulation in the immature fowl by desiccated avian pituitaries. Endocrinology, 62, 84.

Tanaka, K., Kamiyoshi, M. \& Wolford, J. H. (1970) A possible role of LH released soon after ovulation for succeeding ovulation in the hen. Poult. Sci. 49, 1692. 